\title{
Association Analysis of Member RAS Oncogene Family Gene Polymorphisms with Aspirin Intolerance in Asthmatic Patients
}

\author{
Jong-Sook Park, Jeong-Seok Heo, ${ }^{2}$ Hun Soo Chang, ${ }^{2}$ Inseon S. Choi, ${ }^{3}$ Mi-Kyeong Kim, ${ }^{4}$ \\ Jong-Uk Lee, ${ }^{2}$ Byung Lae Park, ${ }^{5}$ Hyoung Doo Shin, ${ }^{5,6}$ and Choon-Sik Park ${ }^{1}$
}

Member RAS oncogene family $(R A B 1 A)$, a member of the RAS oncogene family, cycles between inactive GDP-bound and active GTP-bound forms regulating vesicle transport in exocytosis. Thus, functional alterations of the RABlA gene may contribute to aspirin intolerance in asthmatic sufferers. To investigate the relationship between single-nucleotide polymorphisms (SNPs) in the RABlA gene and aspirin-exacerbated respiratory disease (AERD), asthmatics $(n=1197)$ were categorized into AERD and aspirin-tolerant asthma (ATA). All subjects were diagnosed as asthma on the basis of the Global Initiative for Asthma (GINA) guidelines. AERD was defined as asthmatics showing $15 \%$ or greater decreases in forced expiratory volume in one second $\left(\mathrm{FEV}_{1}\right)$ or naso-ocular reactions by the oral acetyl salicylic acid (ASA) challenge (OAC) test. In total, eight SNPs were genotyped. Logistic regression analysis identified that the minor allele frequency of $+14444 T>G$ and +41170 $C>G$ was significantly higher in the AERD group $(n=181)$ than in the ATA group $(n=1016)(p=0.0003-0.03)$. Linear regression analysis revealed a strong association between the SNPs and the aspirin-induced decrease in $\mathrm{FEV}_{1}(p=0.0004-0.004)$. The RABlA gene may play a role in the development of AERD in asthmatics and the genetic polymorphisms of the gene have the potential to be used as an indicator of this disease.

\section{Introduction}

A SPIRIN-EXACERBATED RESPIRATORY DISEASE (AERD) refers to the development of bronchoconstriction in asthmatics following the ingestion of aspirin (acetyl salicylic acid [ASA]) or other nonsteroidal anti-inflammatory drugs (NSAIDs) (Samter and Beers, 1967). This syndrome is characterized by ASA hypersensitivity, bronchial asthma, nasal polyposis, and chronic hyperplastic eosinophilic sinusitis (Lee and Stevenson, 2011). For other asthmatic individuals, the airways of patients with AERD show signs of persistent inflammation, with marked eosinophilia, epithelial disruption, and cellular proliferation as seen in nasal polyps (NPs) and hyperplastic sinusitis. Multiple points of overproduction or underproduction of critical mediators by a variety of inflammatory cells, including platelets, eosinophils, and neutrophils, probably account for the susceptibility to ASA. These inflammatory cells secrete proteins from intracellular vesicles or granules through exocytosis or degranulation, which is common to all cell types (Siess and Grunberg, 1993; Zerial and McBride, 2001; Lova et al., 2002; Logan et al., 2003). The Ras-like Rab GTPases regulate vesicle transport in endocytosis and exocytosis. There is little definitive evidence supporting the role of Rab proteins in vesicle formation, but their role in subsequent transport and, in particular, targeting is well established. The Ras-related monomeric $\mathrm{G}$ proteins make up a diverse family thought to be involved in intracellular trafficking and distal stages of exocytosis in several kinds of inflammatory and immune cells, including platelets, eosinophils, and neutrophils, which probably account for the susceptibility to ASA. Considering the central role of the Rab GTPases in cellular biogenesis, it is not surprising that the loss or impairment of their activity is involved in a number of human diseases (Lacy et al., 1995). These functions are critically important for all types of cellular growth. Indeed, defective protein transport is associated with the pathogenesis of a variety of human diseases (Guo et al., 2000). A high prevalence of

\footnotetext{
${ }^{1}$ Division of Allergy and Respiratory Medicine, Department of Internal Medicine, Soonchunhyang University Bucheon Hospital, Bucheon, Republic of Korea.

${ }^{2}$ Department of Medical Bioscience, Graduate School, Soonchunhyang University, Asan, Republic of Korea.

${ }^{3}$ Department of Allergy, Chonnam National University, Gwangju, Republic of Korea.

${ }^{4}$ Division of Internal Medicine, College of Medicine, Chungbuk National University, Cheongju, Republic of Korea.

${ }^{5}$ Department of Genetic Epidemiology, SNP Genetics, Inc., Seoul, Republic of Korea.

${ }^{6}$ Department of Life Science, Sogang University, Seoul, Republic of Korea.
} 
member RAS oncogene family (RABlA) overexpression $(93 \%)$ has been observed not only in cancer, but also in premalignant lesions (Olkkonen and Ikonen, 2000). Cellular infiltration and proliferation are the characteristic findings of asthma. Asthmatics with ASA hypersensitivity are more prone to NPs, hyperplastic eosinophilic sinusitis, and increased cell proliferation in the airways, resulting in severe airway obstruction. These data indicate that the genetic alteration of the $R A B 1 A$ gene may be related to the development of asthma and ASA hypersensitivity through the modulation of intracellular protein trafficking. To reveal the genetic role of the $R A B 1 A$ gene in the development of ASA hypersensitivity in asthma, we evaluated the genetic association between single-nucleotide polymorphisms (SNPs) of the $R A B 1 A$ gene and the risk of AERD.

\section{Materials and Methods}

\section{Ethical conduct of research}

Consent to participate in the study was obtained in writing from all subjects. DNA from 181 patients with AERD and 1016 ATA subjects was donated by a biobank at Soonchunhyang University Hospital, Bucheon, Korea (Table 1). The protocal was approved by the ethics committee of Soonchunhyang University Hospital (approval No. SCHBCIRB-2010-005).

\section{Subjects}

The subjects were recruited from the Asthma Genome Research Center, which comprises nine university hospitals in Korea. All subjects were Korean. All patients were diagnosed by physicians and met the definition of asthma set forth in the Global Initiative for Asthma (GINA) guidelines (Bateman et al., 2008). All patients had a history of dyspnea and wheezing during the previous 12 months, plus one of the following: (1) > 15\% increase in forced expiratory volume in one second $\left(\mathrm{FEV}_{1}\right)$ or $>12 \%$ increase plus $200 \mathrm{~mL}$ following inhalation of a short-acting bronchodilator, (2) $<10 \mathrm{mg} / \mathrm{mL}$ $\mathrm{PC}_{20}$ methacholine, and (3) $>20 \%$ increase in $\mathrm{FEV}_{1}$ following 2 weeks of treatment with inhaled steroids and long-acting bronchodilators. Twenty-four common inhalant allergens were used for a skin prick test. Total IgE was measured by the CAP system (Pharmacia Diagnostics, Uppsala, Sweden). Atopy was defined as having a wheal reaction equal to or greater than histamine or $3 \mathrm{~mm}$ in diameter. All study subjects underwent the oral ASA challenge (OAC), and they had experienced no exacerbation of asthma and respiratory tract infection in the 6 weeks preceding OAC. The OAC was performed with increasing doses of ASA following previously described methods with slight modifications (Nizankowska-Mogilnicka et al., 2007; Kim et al., 2010). Changes in $\mathrm{FEV}_{1}$ were followed for $5 \mathrm{~h}$ after the last ASA challenge dose. ASA-induced bronchospasms, as reflected by the rate $(\%)$ of $\mathrm{FEV}_{1}$ decline, were calculated as the prechallenge $\mathrm{FEV}_{1}$ minus the postchallenge $\mathrm{FEV}_{1}$ divided by the prechallenge $\mathrm{FEV}_{1}$. OAC reactions were categorized into two groups as follows: $15 \%$ or greater decreases in $\mathrm{FEV}_{1}$ or nasoocular reactions (AERD) and less than $15 \%$ decreases in $\mathrm{FEV}_{1}$ without naso-ocular or cutaneous reactions (ATA). The protocols were approved by the local ethics committees of each hospital.
Table 1. Clinical Characteristics of the Study Subjects

\begin{tabular}{|c|c|c|}
\hline Clinical profile & $A E R D$ & $A T A$ \\
\hline Number of subjects $(n)$ & 181 & 1016 \\
\hline $\begin{array}{l}\text { Onset of age } \\
\text { [year, median (range)] }\end{array}$ & $40(16-72)$ & $45(11-77)$ \\
\hline Sex $(n$, male/female $)$ & $75 / 106$ & $381 / 635$ \\
\hline $\begin{array}{l}\text { Current smoker/ } \\
\text { ex-smoker }(\%)\end{array}$ & $12.71 / 7.18 *$ & $13.39 / 16.44$ \\
\hline Height $(\mathrm{cm}$, mean \pm SD $)$ & $162.69 \pm 9.72$ & $160.85 \pm 8.97$ \\
\hline Weight $(\mathrm{kg}$, mean $\pm \mathrm{SD})$ & $62.38 \pm 11.03$ & $63.18 \pm 11.23$ \\
\hline $\begin{array}{l}\text { Body mass index } \\
\left(\mathrm{kg} / \mathrm{m}^{2}\right)\end{array}$ & $23.54 \pm 3.49^{*}$ & $24.38 \pm 3.58$ \\
\hline $\begin{array}{l}\% \text { Decline of } \mathrm{FEV}_{1} \\
\text { by aspirin provocation }\end{array}$ & $28.02 \pm 15.31 * *$ & $3.78 \pm 4.82$ \\
\hline Blood eosinophil (\%) & $5.33 \pm 5.46$ & $5.34 \pm 5.02$ \\
\hline $\mathrm{FEV}_{1}(\%$ predicted $)$ & $86.39 \pm 15.81$ & $86.60 \pm 18.13$ \\
\hline $\begin{array}{l}\text { PC20 methacholine } \\
(\mathrm{mg} / \mathrm{mL})\end{array}$ & $4.80 \pm 7.83^{*}$ & $6.71 \pm 8.75$ \\
\hline Total IgE (IU/mL) & $369.30 \pm 597.92$ & $390.89 \pm 629.42$ \\
\hline $\begin{array}{l}\text { Positive rate } \\
\text { of skin test }(\%)\end{array}$ & 52.60 & 51.61 \\
\hline $\begin{array}{l}\text { Positive rate } \\
\text { of nasal polyp (\%) }\end{array}$ & $52.03 * *$ & 22.83 \\
\hline
\end{tabular}

Asterisks represent $p$-values for the comparison of the AERD group to ATA controls using the $t$-test or $\chi^{2}$-test. $* p<0.01$; $* * p<0.0001$.

AERD, aspirin-exacerbated respiratory disease; ATA, aspirintolerant asthma; $\mathrm{FEV}_{1}$, forced expiratory volume in one second.

\section{Genotyping}

A total of eight polymorphisms of the $R A B 1 A$ gene were selected from the National Center for Biotechnology Information (build 36) by the minor allele frequency (MAF) criteria (over 5\% of MAF). Amplification and extension primers were designed for genotyping of the polymorphic sites by single-base extension. All primer extension reactions were performed using the SNaP shot ddNTP Primer Extension Kit (Applied Biosystems, Foster City, $\mathrm{CA}$ ). For subsequent cleanup, the reaction mixture was incubated at $37^{\circ} \mathrm{C}$ for $1 \mathrm{~h}$ with $1 \mathrm{U}$ shrimp alkaline phosphatase, followed by $15 \mathrm{~min}$ at $72^{\circ} \mathrm{C}$ for enzyme inactivation. Then, the extension products and the GeneScan 120 Liz size standard solution were mixed with Hi-Di formamide (Applied Biosystems) according to the manufacturer's recommendations and incubated at $95^{\circ} \mathrm{C}$ for $5 \mathrm{~min}$, followed by 5 min on ice. The mixture was electrophoresed on an ABI Prism 3100 Genetic Analyzer and the results were analyzed using GeneScan and GenoTyper (Applied Biosystems). Information on the primers is shown in Table 2.

\section{Statistics}

We applied widely used measures of linkage disequilibrium (LD) to all pairs of the biallelic loci: Lewontin's D' $\left(\left|\mathrm{D}^{\prime}\right|\right)$ and $r^{2}$ (Barrett et al., 2005). Haplotypes of each individual were inferred using the PHASE algorithm (ver. 2.0) developed by Stephens et al. (2001). The genotype distribution was analyzed using logistic regression models with age (continuous value), gender $($ male $=0$, female $=1)$, smoking status (nonsmoker $=0$, ex-smoker $=1$, smoker $=2$ ), atopy $($ absence $=0$, presence $=1)$, and BMI as covariates. 
Table 2. Sequences of Amplifying and Extension Primers for Genotyping of RABlA Polymorphisms by Single-Base Extension Method

\begin{tabular}{|c|c|c|}
\hline Locus & & Primer sequence \\
\hline$-2232 G>T$ & Forward & 5'-ACTTCGTCAGTAACGGACGGGGAGTATACTTCCCAGGGGAGGA-3' \\
\hline & Reverse & 5'-GAGTCGAGGTCATATCGTGGGGAGTATACTTCCCAGGGGAGGC-3' \\
\hline & Extension & $\begin{array}{l}\text { 5'-AGATTGTATTTTTGGCTGAGGTCCAAAGTCGGAATCGTAGTCGGGTCTGCC } \\
\text { TATAGTGAGTC-3' }\end{array}$ \\
\hline$-1279 T>G$ & Forward & 5'-ACTTCGTCAGTAACGGACTTGTAGGCACTATATAGTGATGAATTGCA-3' \\
\hline & Reverse & 5'-GAGTCGAGGTCATATCGTTTGTAGGCACTATATAGTGATGAATTGCC-3' \\
\hline & Extension & $\begin{array}{l}\text { 5'-ATTTTTATTGCTTATTATTTTCCAGATGCAAGGGCTGCGTTGTCTAGGTCTGCC } \\
\text { TATAGTGAGTC-3' }\end{array}$ \\
\hline$+14444 T>C$ & Forward & 5'-ACTTCGTCAGTAACGGACCACAATTCAAAACCAACCTTCAGGT-3' \\
\hline & Reverse & 5'-GAGTCGAGGTCATATCGTCACAATTCAAAACCAACCTTCAGGC-3' \\
\hline & Extension & $\begin{array}{l}\text { 5'-GAAACACTTACTCCTTGCTGGCCTTGCGTCCGAGAGTAAGGGCGTCTGCCT } \\
\text { ATAGTGAGTC-3' }\end{array}$ \\
\hline$+15676 T>C$ & Forward & 5'-ACTTCGTCAGTAACGGACGGGAATGTTGAAAGTTGGGTTAATGTCA-3' \\
\hline & Reverse & 5'-GAGTCGAGGTCATATCGTGGGAATGTTGAAAGTTGGGTTAATGTCG-3' \\
\hline & Extension & $\begin{array}{l}\text { 5'-TCAGCTTTCTTTTGTAAAGTGTTCCTTATGAATGCGGAGGGTCAAAGGTCTGCC } \\
\text { TATAGTGAGTC-3' }\end{array}$ \\
\hline$+25391 G>T$ & Forward & 5'-ACTTCGTCAGTAACGGACGTGTTGCTCTTAAAAGAAATTCAGTGAAGTA-3' \\
\hline & & 5'-GAGTCGAGGTCATATCGTGTGTTGCTCTTAAAAGAAATTCAGTGAA \\
\hline & Extension & $\begin{array}{l}\text { 5'-GGTTATAAAGTCAGAATGTCTAATACTATTAGCAAGCGCCTCATGTATCGGGTC } \\
\text { TGCCTATAGTGAGTC-3' }\end{array}$ \\
\hline$+28356 A>G$ & Forward & 5'-ACTTCGTCAGTAACGGACAGGGTTTTCCTTGAGGCACAAACA-3' \\
\hline & & 5'-GAGTCGAGGTCATATCGTAGGGTTTTCCTTGAGGCACAAACG-3' \\
\hline & Extension & $\begin{array}{l}\text { 5'-CTGAGGCTACAGCTAGATTCTTCACACGCGGGGTAAACCATTGATCGTCTGCC } \\
\text { TATAGTGAGTC-3' }\end{array}$ \\
\hline$+29857 A>C$ & Forward & 5'-ACTTCGTCAGTAACGGACAGCAAGAAAACAACCAAATGGAAAA-3' \\
\hline & & \\
\hline & Extension & $\begin{array}{l}\text { 5'-GTATTTTGCAGGTTGATAATGGCGCAGTCAACGACGTATTCCGAGTCTGCCTA } \\
\text { TAGTGAGTC-3' }\end{array}$ \\
\hline$+41170 C>G$ & Forward & 5'-ACTTCGTCAGTAACGGACGTCCATTATGGATGGTAGAAATGCAG-3' \\
\hline & & \\
\hline & Extension & $\begin{array}{l}\text { 5'-AAGAATTAGTGAAAAAGATTTTTCTGCACCGTAGACTGCTACAAGGGTC } \\
\text { TGCCTATAGTGAGTC-3' }\end{array}$ \\
\hline
\end{tabular}

RAB1A, member RAS oncogene family.

Haplotype associations were estimated using the HaploScore (www.biostat.wustl.edu/genetics/geneticssoft/). The differences in the rates of decline in $\mathrm{FEV}_{1}$ following the ASA challenge among the genotypes and haplotypes were examined using a linear regression model. The data were managed and analyzed using SAS version 9.1 (SAS, Inc., Cary, NC) and SPSS version 11.0 (SPSS, Inc., Chicago, IL). For the correction of the $p$-values, the effective number of independent markers in $R A B 1 A$ was calculated using the software SNPSpD (http://genepi.qimr.edu.au/general/daleN/SNPSpD), which is based on the spectral decomposition (SpD) of the matrices of pairwise LD between SNPs $(p$-value $\times 59.3221)$ (Nyholt, 2004). The data are expressed as the mean \pm standard error of the mean. Intergroup comparisons were assessed by the Mann-Whitney $U$-test. A $p$-value of $<5 \%$ was considered statistically significant.

\section{Results}

\section{Characteristics of the study subjects}

A total of 1197 subjects were recruited from the asthma cohort. The clinical characteristics of the study subjects are summarized in Table 1. Significant differences in onset of age, prevalence of smoking, FVC, BMI, and rate (\%) of $\mathrm{FEV}_{1}$ decline after ASA challenge were found between the
AERD and the ATA groups $(p<0.05$, Table 1). An ASAinduced decline in $\mathrm{FEV}_{1}$ of $-15 \%$ to $68 \%$ was observed.

\section{Frequency, heterozygosity, and the Hardy-Weinberg equilibrium of SNPs in the RAB1A gene \\ in the study population}

A total of eight polymorphisms of the $R A B 1 A$ gene, which were validated in the National Center for Biotechnology Information (build 36) database, were selected and genotyped in the study subjects. The MAFs of these eight SNPs are summarized in Table 3. The distributions of all loci followed the Hardy-Weinberg equilibrium $(p>0.01)$. The LD coefficients $\left(\left|\mathrm{D}^{\prime}\right|\right)$ and $r^{2}$ among the SNPs of the RAB1A gene were calculated for all study subjects (Fig. 1A, C). Absolute LD $\left(\left|\mathrm{D}^{\prime}\right|=1\right.$ and $\left.r^{2}=1\right)$ was present between $+14444 T>C$ and $+15676 T>C$, between $+25391 G>T$ and $+41170 C>G$, and between $+28356 A>G$ and $+29857 A>C$ on the $R A B 1 A$ gene. $R A B 1 A$ was parsed into two LD blocks (BLs) and there was two major haplotypes for BL1 and three for BL2 (Fig. 1B, C). RAB1A BL1-ht1, BL1-ht2, BL2-ht1, BL2-ht2, and $B L 2-h t 3$ were equivalent to $-2232 G>T,-1279 T>C$, $+41170 C>G,+29857 A>C$, and $+14444 T>C$, respectively. Therefore, the major haplotypes were omitted for further statistical analysis. 
Table 3. The Frequencies, Heterozygosity and HWE of SNPs on RAB1A Gene in the Study Population

\begin{tabular}{|c|c|c|c|c|c|c|c|c|c|c|}
\hline \multirow{3}{*}{$\frac{L o c i}{-2232 G>T}$} & \multirow{3}{*}{$\frac{\text { rs no. }}{\text { rs } 6748462}$} & \multirow{3}{*}{$\begin{array}{l}\text { Position } \\
\text { Promoter }\end{array}$} & & & & & \multirow{3}{*}{$\begin{array}{c}\text { Frequency } \\
0.329\end{array}$} & \multirow{3}{*}{$\begin{array}{c}\text { Heterozygosity } \\
0.441\end{array}$} & \multicolumn{2}{|c|}{$H W E^{\mathrm{a}}$} \\
\hline & & & \multicolumn{4}{|c|}{ Genotype } & & & $A E R D$ & $A T A$ \\
\hline & & & $\begin{array}{r}\mathrm{G} \\
523\end{array}$ & $\begin{array}{l}\mathrm{GT} \\
558\end{array}$ & $\begin{array}{r}\mathrm{T} \\
114\end{array}$ & $\begin{array}{r}\mathrm{N} \\
1195\end{array}$ & & & 0.647 & 0.014 \\
\hline$-1279 T>G$ & rs 2422437 & Promoter & $\begin{array}{r}\mathrm{T} \\
566\end{array}$ & $\begin{array}{r}\text { GT } \\
529\end{array}$ & $\begin{array}{r}\mathrm{G} \\
100\end{array}$ & $\begin{array}{r}\mathrm{N} \\
1195\end{array}$ & 0.305 & 0.424 & 0.715 & 0.060 \\
\hline$+14444 T>C$ & rs 13409078 & Intron 1 & $\begin{array}{r}\mathrm{T} \\
995\end{array}$ & $\begin{array}{r}\text { CT } \\
192\end{array}$ & $\begin{array}{l}\text { C } \\
7\end{array}$ & $\begin{array}{r}\mathrm{N} \\
1194\end{array}$ & 0.086 & 0.158 & 0.387 & 0.081 \\
\hline$+15676 T>C$ & rs 17029863 & Intron1 & $\begin{array}{r}\mathrm{T} \\
995\end{array}$ & $\begin{array}{r}\mathrm{CT} \\
192\end{array}$ & $\begin{array}{l}\text { C } \\
7\end{array}$ & $\begin{array}{r}\mathrm{N} \\
1194\end{array}$ & 0.086 & 0.158 & 0.387 & 0.081 \\
\hline$+25391 G>T$ & rs 2302631 & Intron2 & $\begin{array}{r}\mathrm{G} \\
509\end{array}$ & $\begin{array}{r}\text { GT } \\
553\end{array}$ & $\begin{array}{r}\mathrm{T} \\
129\end{array}$ & $\begin{array}{r}\mathrm{N} \\
1191\end{array}$ & 0.340 & 0.449 & 0.243 & 0.056 \\
\hline$+28356 A>G$ & rs 10195328 & Intron2 & $\begin{array}{r}\mathrm{A} \\
642\end{array}$ & $\begin{array}{l}\mathrm{AG} \\
448\end{array}$ & $\begin{array}{r}\mathrm{G} \\
60\end{array}$ & $\begin{array}{r}\mathrm{N} \\
1190\end{array}$ & 0.255 & 0.308 & 0.148 & 0.021 \\
\hline$+29857 A>C$ & rs 6725335 & Intron2 & $\begin{array}{r}\text { A } \\
642\end{array}$ & $\begin{array}{l}\mathrm{AC} \\
448\end{array}$ & $\begin{array}{r}\mathrm{C} \\
60\end{array}$ & $\begin{array}{r}\mathrm{N} \\
1190\end{array}$ & 0.255 & 0.380 & 0.148 & 0.021 \\
\hline$+41170 C>G$ & rs 1420184 & Intron5 & $\begin{array}{r}\mathrm{C} \\
509\end{array}$ & $\begin{array}{l}\mathrm{CG} \\
553\end{array}$ & $\begin{array}{r}\mathrm{G} \\
129\end{array}$ & $\begin{array}{r}\mathrm{N} \\
1191\end{array}$ & 0.340 & 0.449 & 0.243 & 0.056 \\
\hline
\end{tabular}

${ }^{\mathrm{a}} p$-Values of deviation from HWE in a Korean population.

MAF, minor allele frequency; SNP, single-nucleotide polymorphism; HWE, Hardy-Weinberg equilibrium.

Associations of polymorphisms in the RAB1A gene with the risk of ASA intolerance in asthmatics

All of the polymorphisms of the RAB1A gene and haplotypes were analyzed for associations with the risk of ASA intolerance in asthmatic patients using multiple logistic re- gression models (Table 4). The logistic analysis of the eight SNPs in the RAB1A gene between AERD $(n=181)$ and ATA $(n=1016)$ revealed that two SNPs on the intron $(+14444$ $G>T,+41170 C>G)$ were associated with ASA hypersensitivity $(p=0.0003-0.03$, in the codominant and recessive model). The MAFs of $+14444 G>T$ and $+41170 G>T$

\section{A Map of RAB1A (RAB1A, member RAS oncogene family) on chromosome 2p14 (43kb)}

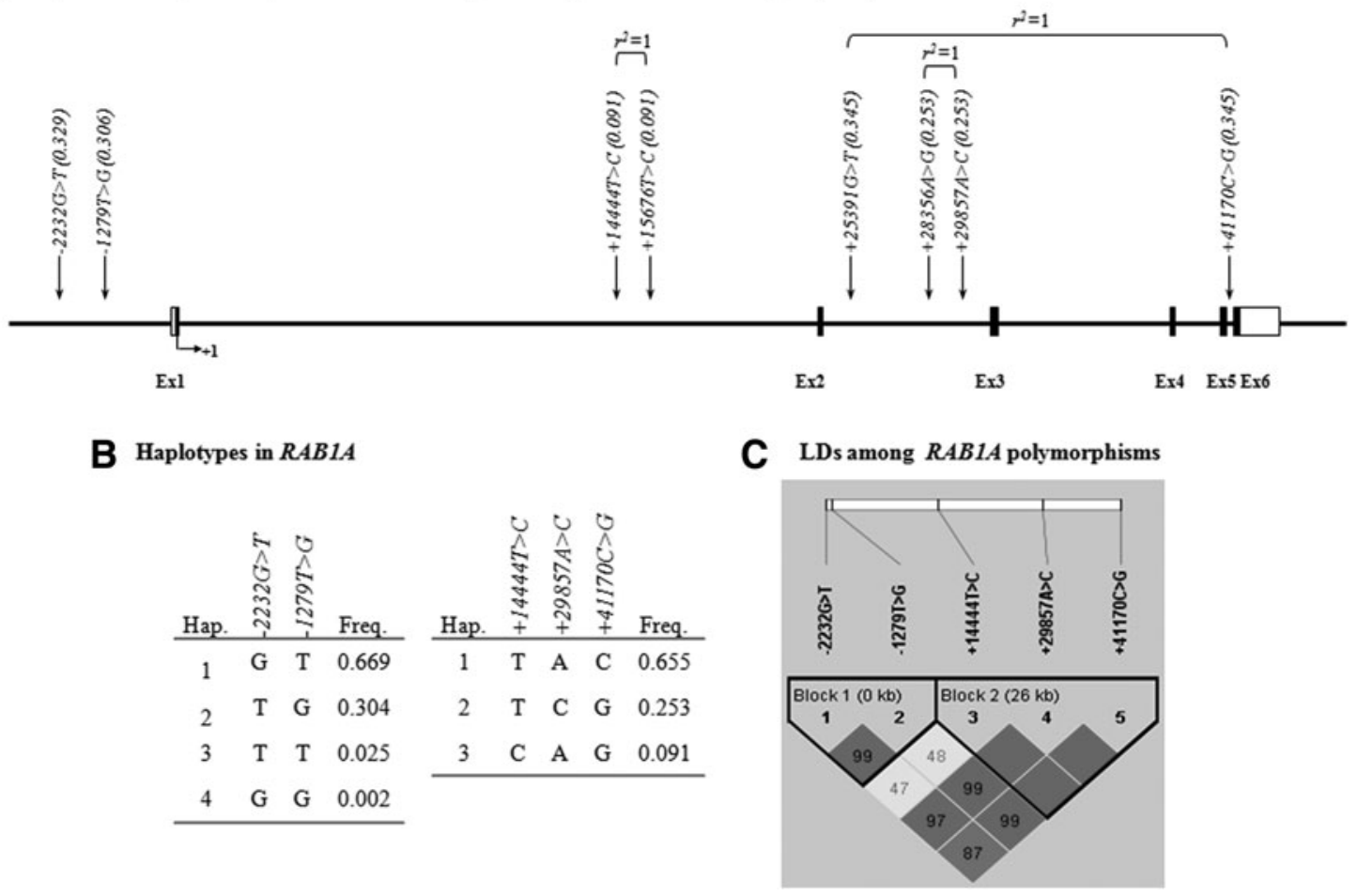

FIG. 1. (A) Schematic gene map and single-nucleotide polymorphisms (SNPs) in the member RAS oncogene family $(R A B 1 A)$ gene on chromosome $2 \mathrm{p}-14(43 \mathrm{~kb})$. Black blocks represent coding exons and white blocks represent $5^{\prime}$ and $3^{\prime}$ UTR. The first base of translation site was denoted as nucleotide +1 . (B) Haplotype of $R A B 1 A$. (C) Linkage disequilibrium (LD) coefficient (|D|') among RAB1A SNPs. 


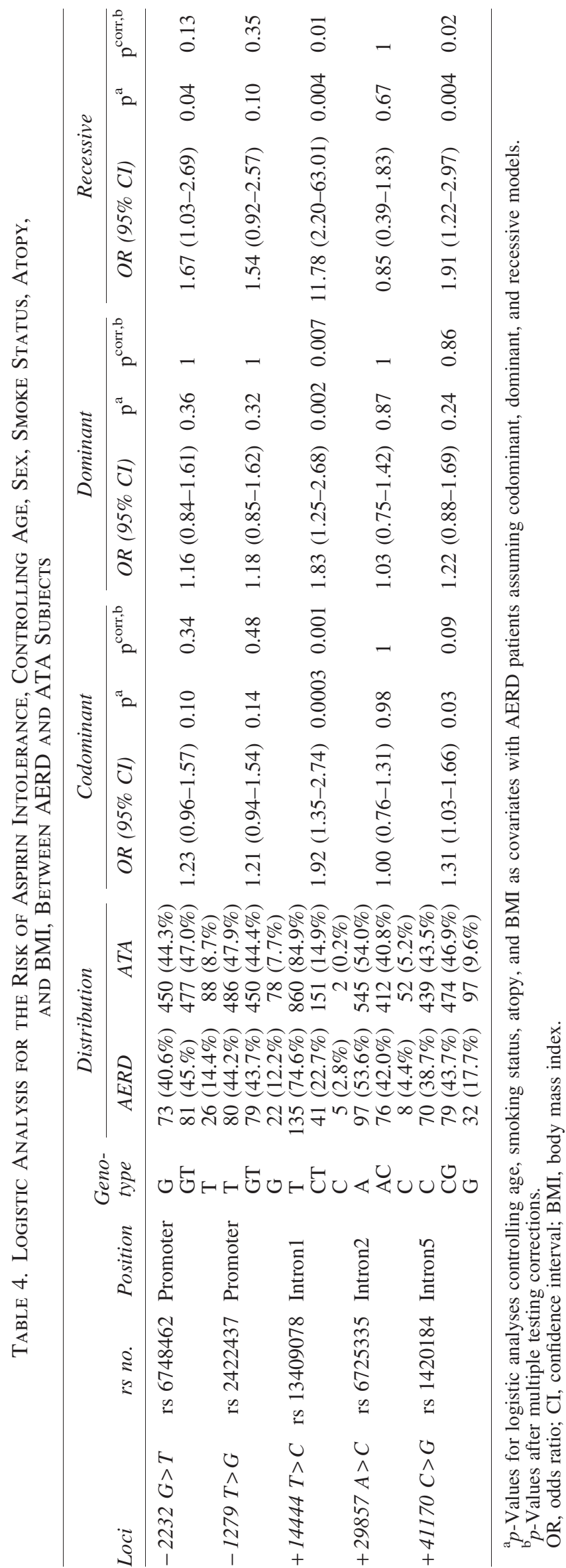

were significantly higher in the AERD group than in the ATA group, and the difference remained after correction for multiple comparisons $\left(p^{\text {corr }}=0.001-0.02\right)$ (Table 2). The frequencies of the haplotypes in RAB1A were not different between the groups.

Because the ASA-induced decline in $\mathrm{FEV}_{1}$ is the most important parameter for the diagnosis of ASA intolerance in asthmatics, we determined the association of the two SNPs with the rate of decline in $\mathrm{FEV}_{1}$ following ASA challenge. Asthmatic patients carrying the minor allele of $+14444 G>T$ showed a greater decline in FEV1 in response to ASA provocation compared with those carrying the common article $(25.36 \pm 18.43 \%$ vs $6.94 \pm 10.73 \%, p=0.0004$; Table 5). Heterozygotes showed the intermediate level of decline in FEV1 between the homozygotes $(9.09 \% \pm 13.47 \%)$. In addition, asthmatics carrying the minor allele of $+41170 C>G$ showed a greater decline in FEV1 compared with those carrying the common allele ( $10.03 \pm 14.13$ vs $6.52 \pm 10.27 \%$, $p=0.004$, Table 5). Heterozygotes showed the intermediate level of decline in FEV1 between the homozygotes (7.62\% \pm $11.55 \%)$.

\section{Discussion}

The human RAB1A gene located on chromosome $2 \mathrm{p} 14$ contains six exons. The Ras-like Rab GTPases regulate vesicle transport in exocytosis, and cardiac rabs 1, 4, and 6 are upregulated in a dilated cardiomyopathy model overexpressing $\beta(2)$-adrenergic receptors (Wu et al., 2001). The results of the present study indicate that GTPase products are altered before and after exposure to ASA/NSAIDs in AERD compared with ATA. In the basal condition before the ASA challenge, metabolites of LTE4 and RAB1A were increased in the urine and airways of AERD compared with ATA. ASA challenge induces an increase in the concentrations of cysteinyl leukotrienes and decreased concentrations of RAB1A in asthmatics (Mastalerz et al., 2012). Based on these data, it is believed that changes to the synthesis of RAB1A are related to ASA hypersensitivity in asthma.

Rab GTPases, although they are the largest subfamily of Ras-like small G proteins, have been overlooked in this regard because they are not signaling molecules. Unlike other Ras-like $\mathrm{G}$ proteins, which are integral members of cellsignaling cascades, Rab GDP/GTP exchange regulates protein internalization and secretion by controlling vesicle docking and fusion throughout the cell (Somsel Rodman and Wandinger-Ness, 2000). These functions are critically important for all types of cellular growth, presumably including that which leads to NPs and hyperplastic eosinophilic sinusitis. The Ras superfamily of GTPases are members of the RAS oncogene family and are heavily expressed in various organs, including the bronchus of the rat lung and the peripheral blood cells, including eosinophils and platelets (Lacy et al., 1995; Burgoyne and Morgan, 2003). Multiple points of overproduction or underproduction of critical inflammatory mediators may be determined by metabolism through the Ras family GTPase pathway (Ferro et al., 2012). The release of specific granules from platelets, eosinophils, and neutrophils depends on the phosphorylation of the Rab proteins, including RAB1A, RAP2, RAB3B, RAB6 and RAB8 (Takai et al., 2001).

The BL2 has six intronic SNPs, among which two $(+14444 G>T$ and $+41170 C>G)$ were associated with 


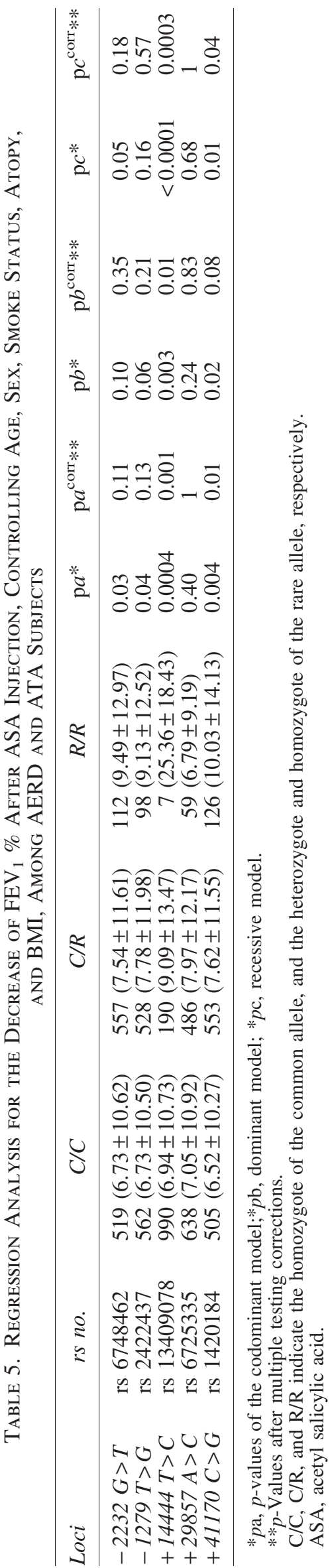

AERD in the present study. It is well known that intronic SNPs can affect transcript processing through alternative splicing or by producing different RNA secondary structures. Thus, we estimated the secondary structures of $R A B 1 A$ mRNA possessing each alleles using Mfold Web Server (http://mfold.rna.albany.edu/?q=mfold). The free energy change $(\triangle \mathrm{G})$ of $R A B 1 A \mathrm{mRNA}$ containing the minor alleles of $+14444 G>T$ and $+41170 C>G$ was $-78.72 \mathrm{kcal} / \mathrm{mol}$, while that having the common allele was $-76.10 \mathrm{kcal} / \mathrm{mol}$. These suggest a possibility that these SNPs may affect the secondary structure of the RAB1A mRNA. In addition, we searched the splicing segments around $+14444 G>T$ and $+41170 C>G$ using a splicing prediction tool, Human Splicing Finder Version 2.4.1 (www.umd.be/HSF). + 14444 $G>T$ could not be analyzed using this tool because its location was far from the exon-intron boundary, but +41170 $C>G$ in intron5 was predicted to be the third base upstream from the splicing branch point. There have been four transcription variants in the NCBI database. Among them, variant 2 is an alternative splicing form lacking exon 4 and 5. This suggests that the production of spliced variants of $R A B 1 A$ might be affected by $+41170 C>G$. However, the functional effects of these SNPs should be evaluated in the future.

It has been well known that the proportion of patients suffering from NPs is higher in AERD than in ATA (Fahrenholz, 2003). In the present study (Table 1), and our previous publication (Chang et al., 2011), the proportion of patients with NP was significantly higher in Korean patients with AERD than in ATA subjects. Thus, the association of $+14444 G>T$ and $+41170 C>G$ with AERD in the present study could be a result of the association with NP. However, neither $+14444 G>T$ nor $+41170 C>G$ were associated with the presence of NP in the present study $(p>0.05$, Supplementary Table S1; Supplementary Data are available online at www.liebertpub.com/dna).

\section{Conclusion}

The present study investigated the associations of SNPs on the $R A B 1 A$ gene with the risk of AERD. We genotyped eight human $R A B 1 A$ SNPs and examined their links to AERD and the responsiveness of airways to ASA in asthmatic patients. Two SNPs $(+14444 T>C$ and $+41170 C>G)$ were associated with ASA hypersensitivity in asthma. The $R A B 1 A$ gene may play a role in the development of AERD in asthmatics and the genetic polymorphisms of the gene have the potential to be used as an indicator of this disease.

\section{Acknowledgments}

Plasma samples were generously provided by the Soonchunhyang University Bucheon Hospital Biobank (approval No. SCHBC-IRB-2010-005), a member of the National Biobank of Korea, supported by the Ministry of Health, Welfare and Family Affairs, Republic of Korea. This study was supported by the National Research Foundation of Korea (NRF) grant funded by the Korea government (MEST) 2012R1A1A2038396) and the Ministry of Health, Welfare and Family Affairs, Republic of Korea (HI13C0319).

\section{Disclosure Statement}

No competing financial interests exist. 


\section{References}

Barrett, J.C., Fry, B., Maller, J., and Daly, M.J. (2005). Haploview: analysis and visualization of LD and haplotype maps. Bioinformatics 21, 263-265.

Bateman, E.D., Hurd, S.S., Barnes, P.J., Bousquet, J., Drazen, J.M., FitzGerald, M., Gibson, P., Ohta, K., O’Byrne, P., Pedersen, S.E., Pizzichini, E., Sullivan, S.D., Wenzel, S. E., and Zar, H.J. (2008). Global strategy for asthma management and prevention: GINA executive summary. Eur Respir J 31, 143-178.

Burgoyne, R.D., and Morgan, A. (2003). Secretory granule exocytosis. Physiol Rev 83, 581-632.

Chang, H.S., Park, J.S., Jang, A.S., Park, S.W., Uh, S.T., Kim, Y.H., and Park, C.S. (2011). Diagnostic value of clinical parameters in the prediction of aspirin-exacerbated respiratory disease in asthma. Allergy Asthma Immunol Res 3, 256-264.

Fahrenholz, J.M. (2003). Natural history and clinical features of aspirin-exacerbated respiratory disease. Clin Rev Allergy Immunol 24, 113-124.

Ferro, E., Goitre, L., Retta, S.F., and Trabalzini, L. (2012). The interplay between ROS and Ras GTPases: physiological and pathological implications. J Signal Transduct 2012, 365769.

Guo, W., Sacher, M., Barrowman, J., Ferro-Novick, S., and Novick, P. (2000). Protein complexes in transport vesicle targeting. Trends Cell Biol 10, 251-255.

Kim, B.S., Park, S.M., Uhm, T.G., Kang, J.H., Park, J.S., Jang, A.S., Uh, S.T., Kim, M.K., Choi, I.S., Cho, S.H., Hong, C.S., Lee, Y.W., Lee, J.Y., Choi, B.W., Park, H.S., Park, B.L., Shin, H.D., Chung, I.Y., and Park, C.S. (2010). Effect of single nucleotide polymorphisms within the interleukin-4 promoter on aspirin intolerance in asthmatics and interleukin4 promoter activity. Pharmacogenet Genomics 20, 748-758.

Lacy, P., Thompson, N., Tian, M., Solari, R., Hide, I., Newman, T.M., and Gomperts, B.D. (1995). A survey of GTP-binding proteins and other potential key regulators of exocytotic secretion in eosinophils. Apparent absence of rab3 and vesicle fusion protein homologues. J Cell Sci 108(Pt 11), 3547-3556.

Lee, R.U., and Stevenson, D.D. (2011). Aspirin-exacerbated respiratory disease: evaluation and management. Allergy Asthma Immunol Res 3, 3-10.

Logan, M.R., Odemuyiwa, S.O., and Moqbel, R. (2003). Understanding exocytosis in immune and inflammatory cells: the molecular basis of mediator secretion. J Allergy Clin Immunol 111, 923-932; quiz 933.

Lova, P., Paganini, S., Sinigaglia, F., Balduini, C., and Torti, M. (2002). A Gi-dependent pathway is required for activation of the small GTPase Rap1B in human platelets. J Biol Chem 277, 12009-12015.

Mastalerz, L., Sanak, M., Kumik, J., Gawlewicz-Mroczka, A., Celejewska-Wojcik, N., Cmiel, A., and Szczeklik, A. (2012).
Exhaled eicosanoids following bronchial aspirin challenge in asthma patients with and without aspirin hypersensitivity: the pilot study. J Allergy (Cairo) 2012, 696792.

Nizankowska-Mogilnicka, E., Bochenek, G., Mastalerz, L., Swierczynska, M., Picado, C., Scadding, G., Kowalski, M.L., Setkowicz, M., Ring, J., Brockow, K., Bachert, C., Wohrl, S., Dahlen, B., and Szczeklik, A. (2007). EAACI/GA2LEN guideline: aspirin provocation tests for diagnosis of aspirin hypersensitivity. Allergy 62, 1111-1118.

Nyholt, D.R. (2004). A simple correction for multiple testing for single-nucleotide polymorphisms in linkage disequilibrium with each other. Am J Hum Genet 74, 765-769.

Olkkonen, V.M., and Ikonen, E. (2000). Genetic defects of intracellular-membrane transport. N Engl J Med 343, 10951104.

Samter, M., and Beers, R.F., Jr. (1967). Concerning the nature of intolerance to aspirin. J Allergy 40, 281-293.

Siess, W., and Grunberg, B. (1993). Phosphorylation of rap1B by protein kinase $\mathrm{A}$ is not involved in platelet inhibition by cyclic AMP. Cell Signal 5, 209-214.

Somsel Rodman, J., and Wandinger-Ness, A. (2000). Rab GTPases coordinate endocytosis. J Cell Sci 113(Pt 2), 183 192.

Stephens, M., Smith, N.J., and Donnelly, P. (2001). A new statistical method for haplotype reconstruction from population data. Am J Hum Genet 68, 978-989.

Takai, Y., Sasaki, T., and Matozaki, T. (2001). Small GTPbinding proteins. Physiol Rev 81, 153-208.

Wu, G., Yussman, M.G., Barrett, T.J., Hahn, H.S., Osinska, H., Hilliard, G.M., Wang, X., Toyokawa, T., Yatani, A., Lynch, R.A., Robbins, J., and Dorn, G.W., 2nd (2001). Increased myocardial Rab GTPase expression: a consequence and cause of cardiomyopathy. Circ Res 89, 1130-1137.

Zerial, M., and McBride, H. (2001). Rab proteins as membrane organizers. Nat Rev Mol Cell Biol 2, 107-117.

$$
\begin{array}{r}
\text { Address correspondence to: } \\
\text { Choon-Sik Park, MD, PhD } \\
\text { Division of Allergy and Respiratory Medicine } \\
\text { Department of Internal Medicine } \\
\text { Soonchunhyang University Bucheon Hospital } \\
\text { 1174, Jung Dong, Wonmi Ku } \\
\text { Bucheon 420-021 } \\
\text { Republic of Korea }
\end{array}
$$

E-mail: mdcspark@hanmail.net

Received for publication October 6, 2013; received in revised form December 3, 2013; accepted December 10, 2013. 